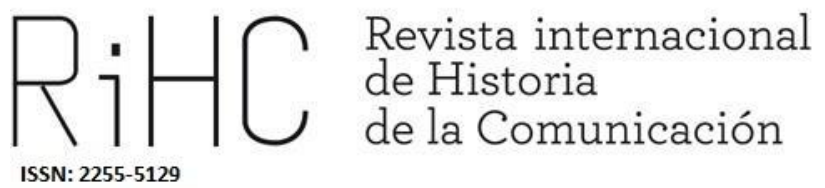

\title{
LAS PRIMITIVAS RECEPCIONES \\ DE LA TELEVISIÓN EN ESPAÑA: \\ LA BRITISH BROADCASTING \\ CORPORATION (BBC) SE \\ SINTONIZÓ ANTES QUE \\ TELEVISIÓN ESPAÑOLA (TVE) \\ EN ASTURIAS
}

The original receptions of television in Spain: the British Broadcasting Corporation (BBC) was tuned before spanish television (TVE) in Asturias

DOI: https://dx.doi.org/10.12795/RiHC.2020.i15.10

Recibido: 23-08-2020

Aceptado: $10-11-2020$

Publicado: $30-12-2020$

Martín-Antón, Javier

Universidad de Oviedo, España

martinajavier@uniovi.es

ORCID (iD 0000-0002-6698-6736

Como citar este artículo: MARTÍN-ANTÓN, Javier (2020): “Las primitivas recepciones de la televisión en españa: la British Broadcasting Corporation (BBC) se sintonizó antes que televisión española (TVE) en Asturias", en Revista Internacional de Historia de la Comunicación, (15), pp. 189-211. 
Resumen: La presente investigación sobre la historia de la televisión y su implantación territorial ha sacado a la luz algunas singularidades y ha puesto de relieve incorreciones que se han dado como válidas durante más de medio siglo. El procedimiento utilizado se ha basado en la revisión y exhumación de fuentes y en la obtención de testimonios inéditos. Para ello nos hemos centrado en una provincia-Asturias, España-para la que proporcionamos una nueva cronología que incluye sucesos olvidados $\mathrm{y} / \mathrm{o}$ desconocidos hasta el presente. Nuestra aportación supone, por un lado, una revisión histórica de la implantación de la televisión que aporta una corrección y concreción de los sucesos necesaria para que evitar errores en futuros trabajos docentes y de investigación y, por otro lado, una invitación a la revisión del fenómeno televisivo y su cronología en otras regiones en las que pueden haberse producido semejanzas con los hallazgos que aquí exponemos.

Palabras clave: televisión; historia de la televisión; revisionismo histórico; televisión en España; televisión en Asturias, BBC, TVE.

\begin{abstract}
The present investigation on the history of television and its territorial implantation has brought to light some singularities and has highlighted inaccuracies that have been considered valid for more than half a century. The procedure used has been based on the review and exhumation of sources and on obtaining unpublished testimonies. To do this we have focused on a province - Asturias, Spain - for which we provide a new chronology that includes forgotten and/or unknown events up to the present. Our contribution supposes, on the one hand, a historical review of the implementation of television that provides a correction and specification of the events necessary to avoid errors in future teaching and research work and, on the other hand, an invitation to review the television phenomenon and its chronology in other regions in which there may have been similarities with the findings that we present here.
\end{abstract}

Keywords: television; television history; historical revisionism; television in Spain; television in Asturias, BBC, TVE.

\title{
1 Introducción y estado de la cuestión
}

Cuando se imparten y se divulgan sucesos históricos es esperable que la cronología sea lo más precisa posible. Determinar la implantación de la televisión y sus primeras sintonizaciones en un territorio es una cuestión relevante porque la llegada de la televisión, tal y como destaca Palacio (2001), supone un importante impacto social en el momento que sucede.

En una mirada al pasado, vemos a la televisión como un fenómeno reciente, y ello ha supuesto que en sus orígenes no suscitase una profusa investigación. Una cuestión esta 
que se resolvió con el trascurrir de los años, generando un creciente interés que convirtió a la pequeña pantalla en objeto de estudio desde diferentes prismas.

Si atendemos a los estudios realizados en materia televisiva desde una perspectiva histórica, en el ámbito nacional y sin acometer una exhumación bibliográfica exhaustiva, encontramos abundantes trabajos de autores como: Arias (1970), Baget Herms (1993), Díaz (1994), Ruíz del Olmo (1997), Palacio (2001), Melgar (2003), Laffond y Chicharro (2006), Bustamante (2013) entre otros investigadores.

Cuando nos fijamos en trabajos que abordan el fenómeno de la televisión en territorios más reducidos y concretos -televisiones regionales o locales- hallamos menos estudios y los que encontramos afrontan los aspectos históricos de un modo más liviano debido a que su atención se suele centrar en cuestiones relacionadas con las audiencias y/o la implantación de las cadenas locales y/o regionales. Sirvan de ejemplo: Navarro Moreno (1999), Santos y Pérez (2010), Sabés (2002) y Ortega (2008) entre otros.

A consecuencia de ello, la llegada de la televisión a los diferentes puntos del país ha quedado relegada a un segundo plano o solamente Televisión Española (en adelante, TVE) ha sido objeto de estudios más profundos obviándose la recepción de otras televisiones que se sintonizaron antes de la llegada de la cadena estatal. Es inabarcable, en este artículo, realizar una revisión historiográfica territorio por territorio así que nos hemos centrado en un caso: la Comunidad Autónoma del Principado de Asturias (España). Para este espacio geográfico comprobamos la escasez de estudios que acomenten la perspectiva histórica de la televisión en la provincia.

Las publicaciones que encontramos y que se centran en esta región no buscan el rigor histórico, debido a que su cometido no es otro que el del entretenimiento del lector, o sus objetivos de investigación distan de centrarse en la historiografía de este medio de comunicación. Aquellas obras dedicadas al entretenimiento lo logran recopilando anécdotas de los primeros redactores de TVE en Asturias y sus vicisitudes profesionales; ejemplo de ello son los trabajos de Tamargo (1991) y Fernández Avello (1976).

Por otra parte, tampoco encontramos una profunda reflexión sobre la llegada de la televisión en una obra que se considera un referente bibliográfico regional y, por tanto, cita forzosa de la mayor parte de los textos académicos y/o divulgativos publicados en la provincia. Se trata de la Gran Enciclopedia Asturiana (en adelante, GEA). En ella se recoge la voz "televisión" para Asturias y dice textualmente:

Si bien desde el año 1961 comenzó a verse la televisión en alguna zona de Asturias, como consecuencia de las reemisoras que se montaron en Gijón, Mieres y Sama, las cuales conectaban con Oviedo en la zona conocida como El Cristo de las Cadenas, el cual enlazaba directamente con Navacerrada, al igual que el de Avilés, la realidad es que el funcionamiento de la televisión de una manera regular no se 
produjo hasta el año 1964, en que se inauguró la instalación de Gamoniteiro (Cañada et al., 1993: 273)

La GEA sitúa la llegada de la señal en 1961. Expresamente dice "verse la televisión" sin matizar - aunque por el contexto, se puede deducir - si se refiere a TVE o si se comenzó a verse otra televisión que no fuese TVE. La aportación de la GEA se traslada a posteriores estudios en los que, como el de Suárez (2004), tampoco se hace distinción alguna ni se entra en mayores concreciones.

Por otra parte, también hemos tratado de exhumar fuentes primarias sobre la llegada de la televisión a la provincia; pero estas se reducen a exigua documentación que ha sobrevivido a diferentes expurgos y toda ella corresponde exclusivamente a TVE. Esta ausencia de documentos es inherente al objeto de nuestro estudio: la televisión. Una materia injustamente tratada en el ámbito de la conservación documental al no ser considerada de interés sociocultural desde sus inicios (Gómez Alonso, 2004). Tampoco encontramos material filmado que recogiera las primeras recepciones de la televisión en aquellos primeros instantes en los que no se contaba con una tecnología que lo hubiera hecho posible. Tan solo hallamos alguna fotografía recogida en la prensa regional y realizada a televisores que nos ayudan a constatar alguna recepción de la señal de TVE, pero no son instantáneas que nos muestren la imagen de recepciones anteriores a las de la cadena pública española.

En lo referido a trabajos académicos, es notoria la escasez de compendios en los que la televisión en Asturias sea la protagonista. En los estudios que existen apenas se aborda de un modo tangencial la cronología, pues no precisan hacerlo para los enfoques que adoptan ni los asuntos en los que profundizan y tratan. A continuación, se presenta un breve recorrido por los autores que abordaron el asunto de la televisión en la región asturiana.

Comenzamos mencionando un estudio de tesina de licenciatura (Bango, 2004) que centra su atención exclusivamente en TVE. Cuando, el citado autor se refirió a la llegada de la cadena pública la fijó en el día 23 de noviembre de 1960. Pero Bango no procura ningún dato, al no ser este el objeto de estudio de su investigación, que pueda sugerir recepciones previas a la de TVE.

Coincidió cronológicamente con Bango (2004) el trabajo de Rodríguez et al (2011) quienes aseguran que: "A finales de 1960 se comenzaba a ver la televisión en Oviedo» (Rodríguez et al. 2011: 544). También observamos que se utilizó el sustantivo "televisión" sin concretar si específicamente se están refiriendo a TVE o la televisión en general. Una vez más, debemos suponer por el contexto de su estudio que se señala a TVE. 
De un modo paralelo y simultáneo abordamos, a continuación, a dos autores que publicaron sus trabajos en lengua asturiana. Sánchez Antuña (2011) y Ruitiña (2013). Para ambos, la televisión llegó a Asturias en 1964.

Según recoge Sánchez Antuña en su obra - véase traducción del asturiano al pie de página- «El 29 de xineru de 1964 ye una fecha perimportante na historia reciente d'Asturies y paradoxicamente malpenes se noma nos llibros. Esi dia, por primer vez, viose la televisión n'Asturias. D'ello hai mui poco, cuasi nada, escrito» (Sánchez Antuña, 2011: 24). ${ }^{1}$

Ruitiña, por su parte, en su estudio - también escrito en asturiano- aseguró: «Y, tovía en 1960, la década na que llega la televisión a Asturies...» (Ruitiña, 2013: 11). ${ }^{2}$ Como vemos, en ambos casos no se señala otra televisión diferente a TVE, de la que se deduce que hablan por el contexto general de su trabajo.

La lista de investigadores la finalizamos con el reciente estudio de Cañedo (2018). En este trabajo la investigadora fijó el 30 de enero año 1964 como el momento en que llegó la señal de la televisión pública española sin realizar otras matizaciones.

\section{Objetivo de la investigación}

Observamos que, en todos los estudios realizados hasta la actualidad, se han considerado coincidentes la primera recepción de la televisión y la llegada de TVE sin que hasta ahora se estableciese una dicotomía y se señalase una diferencia entre ambos hitos al darse por supuesto, al menos de manera implícita, que no hubo recepciones anteriores a la de TVE. A la vista de ello consideramos que es necesario efectuar una revisión del fenómeno ya que la cronología sobre la televisión en Asturias se nos antoja poco explorada y confusa.

En consecuencia, hemos fijamos los siguientes objetivos para aportar luz al asunto. Por un lado, exhumar e investigar si se llevaron a cabo recepciones de televisión previas a la llegada de TVE y, por otro lado, y en caso de confirmarse estas, realizar una separación clara proponiendo la distinción terminológica para distinguir entre las primeras recepciones de la televisión y las primeras recepciones de TVE.

\footnotetext{
1 Traducción del Autor del asturiano al español (en adelante, TA): “El 29 de enero de 1964 es una fecha muy importante en la historia reciente de Asturias y paradójicamente a penas se nombra en los libros. Ese día, por primera vez, se vio la televisión en Asturias. De ello hay muy poco, casi nada, escrito."

2 TA: "Y todavía en 1960, la década en la que llega la televisión a Asturias".
} 
En otras palabras, el propósito principal de la presente investigación es verificar y exponer la fecha y las pruebas que demuestran cuándo, quién y en dónde se sintonizó, por primera vez, una señal de television en la provincia de Oviedo (actualmente, comunidad autónoma del Princiado de Asturias y en adelante, Asturias).

\section{Metodología}

La herramienta de investigación protagonista en nuestro estudio ha sido la recogida y el análisis de testimonios orales. Esta metodología la hemos utilizado con informantes relevantes cuyas aportaciones ayudan a esclarecer las primeras recepciones de la televisión en Asturias. Sin embargo, este método de estudio, a pesar de la notabilidad de lo que pueden aportar, no ha sido utilizado en ningún estudio anterior al nuestro que abordase la llegada de la televisión a la mencionada región.

Debemos destacar que, en la actualidad, no abundan los informantes que fueran testigos de aquellas primeras recepciones de la television y a los que denominaremos caza señales; unos románticos que buscaban sintonizar la televisión en la segunda mitad de la década de los años 50 del siglo pasado. Ellos eran habitualmente "técnicos cualificados y curiosos que dedicaron tiempo y esfuerzo a lograr recepciones aleatorias de señales de televisión» (Martín-Antón, 2017b: 36).

En el desarrollo de nuestra investigación hemos contado con la experiencia testimonial de dos caza señales, - uno en Gijón y otro en Oviedo- que estuvieron ligados de un modo directo a las primeras recepciones en Asturias. Nuestro informante gijonés es Mercurio Martínez García. Su padre, ya fallecido, Mercurio Martínez Rodríguez era perito industrial con amplios conocimientos electrónicos y regentaba un conocido negocio local dedicado a la electrónica y electricidad.

En cuanto a nuestro informante ovetense se trata de Juan Eladio Llaneza Carral. Su padre, también fallecido, era Juan Eladio Llaneza Fernández, doctor Ingeniero de Caminos, Canales y Puertos y responsable de la empresa Radioeléctrica Castellana S.A., una compañía dedicada a las telecomunicaciones, cuya sede estaba ubicada en la capital asturiana.

Los progenitores de nuestros informantes contaban con una elevada cualificación profesional técnica y mucha curiosidad por la televisión y, nuestros dos informantes fueron testigos directos de los experimentos realizados por sus respectivos padres mientras estos intentaban captar las primeras señales de la televisión en Asturias. Ambos nos han aportado información relevante para constatar y documentar las primeras recepciones de la televisión en la región. 
Para realizar las entrevistas a nuestros informantes se ha utilizado un diálogo abierto. Fueron grabadas en video y se conservan los originales y sus transcripciones.

El trabajo con fuentes orales supone atender a una serie de precauciones necesarias para validarlas mediante un permanente contraste de la información, como señala Guixé (2017: 391). Por eso, tras la revisión y trascripción de las entrevistas, se ha confirmado cada dato obtenido con artículos y reportajes que aparecieron en los periódicos regionales y/o locales en las mismas fechas. Para nuestra investigación, esta labor ha resultado indispensable y muy enriquecedora y nos ha llevado a comprender mejor a Hernández Ramos (2017: 470) cuando aseguraba que el uso de los periódicos es una herramienta imprescindible para el historiador ya que: «[...] ofrece al investigador una mirada al pasado de carácter único, inencontrable en cualquier otra fuente». Efectivamente así ha sido. La prensa contribuye a nuestra investigación, por un lado, proporcionando informaciones que tuvieron que ver con la captación de señales. En los diarios aparecieron noticias que recogieron algunas recepciones llevadas a cabo por caza señales y entre ellos, precisamente, aparecen los que nos desvelaron nuestros informantes. Por otro lado, tal y como se concluye en Martín-Antón (2017a), los rotativos nos exponen el interés creciente de los asturianos por el asunto televisivo que se hizo patente mediante un significativo aumento de las informaciones, sobre todo en el último trimestre de 1959.

En otro orden de cosas, destacamos que al aproximarnos a este objeto de estudio y obtener los primeros datos, nos planteamos la posibilidad de que tanto la prensa como los informantes, movidos por la pasión, exagerasen al hablar de recepciones de señales procedentes de lugares lejanos. Desde el punto de vista técnico, en aquellos años, las emisiones de televisión sufrieron enormes deficiencias que afectaban al alcance, a la calidad de la emisión y por supuesto a la recepción. Desconocedores de este asunto que corresponde más al conocimiento de las telecomunicaciones decidimos incluir, en nuestro método de trabajo, una tercera comprobación o medio de contraste sobre la información que nos aportaban tanto los informantes como la prensa. Para ello realizamos dos procesos: uno de verificación y otro de constatación. El proceso de verificación se utilizó para comprobar si las televisiones extranjeras que se afirmaba que se recibieron en Asturias estaban emitiendo en las fechas en las que se aseguraba que fueron sintonizadas. Por su parte, el proceso de constatación nos sirvió para comprobar y evidenciar si era factible, con la tecnología de aquel momento, que dichas señales de cadenas extranjeras alcanzasen físicamente la citada región. En esta fase de constatación dispusimos de otros dos informantes que, gracias a su cualificación y razón de ciencia, nos han ayudado a comprender y por lo tanto a conocer argumentos que nos han servido para confirmar cómo se vio afectada la señal de televisión por factores atmosféricos y astronómicos y como estos factores pueden afectar a la propagación de dicha señal logrado recepciones de larga distancia, como veremos que sucedió en Asturias. Estos dos especialistas han sido Javier Alcolea Jiménez, doctor en ciencias 
físicas y astrónomo responsable del Observatorio Astronómico de Madrid y Susana Loredo Rodríguez, doctora ingeniera de telecomunicación e investigadora en el área de Teoría de la Señal y Comunicaciones de la universidad de Oviedo.

\section{Resultados}

\subsection{La televisión en Asturias hasta octubre de 1956}

La primera vez que aparecen noticias sobre la televisión vinculadas a la región asturiana fue en el año 1952 con motivo de la finalización de la torre central de la Universidad Laboral José Antonio Girón en Gijón. El proyecto arquitectónico, con un diseño inspirado en El Escorial, fue durante años exhibido como uno de los grandes logros del régimen franquista. El edificio estaba destinado a ser orfelinato minero y nunca tuvo vinculación alguna con la televisión. ${ }^{3}$ Sin embargo se pretendió instalar en este edificio una antena de televisión de grandes dimensiones. Así lo recogió el diario nacional $A B C$ : «Sobre la torre irá la antena de televisión, que empezará a construirse en breve y que tendrá 18 metros, lo que hace que la altura total sea de 124 metros» (30 de agosto de 1952: 18).

La información anterior nos resultó inquietante si tenemos en cuenta que, en 1952, no existe aún ninguna cadena de televisión radiando en España. Comprobamos además que antes y después de la fecha del artículo, ni los medios escritos locales ni regionales hicieron ninguna alusión sobre este asunto de la antena por lo que podemos asegurar que nunca se ejecutó dicha obra.

Sin embargo, pocos días después de esta noticia, un comercio gijonés puso a la venta el primer receptor de televisión del que se tiene constancia en Asturias. El aparato se exhibió en el escaparate de la tienda de electricidad propiedad de Mercurio Martínez Rodríguez quien ya mostraba un especial interés por la televisión. El receptor estaba, por supuesto, apagado.

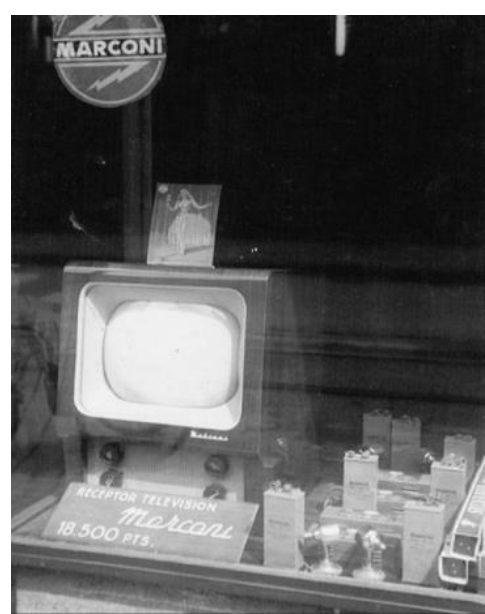

Figura 1. Primer televisor expuesto en un escaparate de la región. Año 1952. Fuente: fotografía cedida por Mercurio Martínez Rodríguez

\footnotetext{
${ }^{3}$ Sirva como curiosidad que en la actualidad parte de las instalaciones de la Universidad Laboral de Gijón son sede de la Televisión Autonómica del Principado.
} 
Se trataba de un modelo Marconi cuyo precio era de dieciocho mil quinientas pesetas (111,19 Euros). Una fotografía fechada es su parte posterior en el año 1952 se convierte en prueba documental (ver Figura 1).

La televisión fue un tema ausente en los medios de prensa asturianos entre 1952 y 1956. No era del interés de la población. A los asturianos, aún muy distantes de gozar de esta tecnología, este asunto les resultaba más propio de la ciencia ficción que de una próxima realidad.

En otro orden de cosas, antes de 1956 no hubo recepciones de señales de televisión en Asturias. El resultado de nuestra investigación indica que no hay ninguna prueba documental de ello, no existen informantes que corroboren lo contrario y, además, la prensa no se hizo eco de ninguna recepción. Comprobamos además que cuando se produjeron de una manera asidua las primeras recepciones de señales de TVE, los rotativos se hicieron eco de ellas bajo destacados y titulares, convirtiendo el asunto televisivo en noticia de interés general. Las propias evidencias de las circunstancias hacen descabellado el pensar en la recepción de señales de televisión, aunque procediesen del extranjero, antes 1956. Hacemos notar que para que algún caza señales hubiera obtenido resultados positivos debieron confluir en él estas circunstancias:

1) Que creyese que pudiera recibir en su casa una señal de televisión procedente de cualquier parte del mundo - ya que en España no se emitía aún TVE- y esto le despertase el suficiente interés por intentarlo. Además de tener fe en que sucediese dicho suceso era preciso que tuviera conocimientos técnicos y cualificación profesional suficiente como para montar una instalación, o que contase con especialistas técnicos a su servicio, algo muy escaso y costoso en nuestro país en aquel momento.

2) Disponer de recursos económicos y tecnológicos suficientes para construir una compleja y costosa instalación dotada de una antena de grandes dimensiones. Al no funcionar aún reemisores de señal fijos no existen puntos exactos hacia los cuales orientar esa supuesta antena. Por lo tanto, la antena debía ser un modelo de recepción orientable y de fabricación propia, ya que no se comercializaban en España nada similar. Y por supuesto, debió disponer de un televisor. Algo que no era fácil de obtener en la década de 1950. Los receptores de televisión eran escasos, puesto que no se fabricaban en España, y su precio era muy elevado.

3) En el supuesto de que el caza señales tuviera un televisor y una instalación, el receptor debió de estar fabricado sin un estándar técnico - ya que en Europa aún no existe uno homologado para todos los países - Por ello, a los televisores elaborados fuera de España, que eran los que pudieron llegar a las manos de nuestro presunto caza señales, se les aplicaba la Norma Gerber -también conocida como norma Marconi-EMI- que implantaba. Los parámetros de 
fabricación recomendados por el Comité Consultativ Internacional des Radiocommunications (CCIR) en 1950 (Limann, 1988: 4) y que eran criterios de libre aplicación. Por ello, los televisores eran poco útiles para recibir con buena calidad las señales de un país diferente al de su fabricación y, por tanto, sólo sintonizaban con calidad en el territorio para el que fueron diseñados.

4) Finalmente, aun en el caso de que hubieran confluido de una manera favorable todas las circunstancias expuestas anteriormente en nuestro hipotético caza señales, este debió de contar con el factor suerte. Las señales de televisión de cadenas extranjeras que viajaban por la atmósfera no estaban pensadas para verse expresamente en Asturias; por tanto, no hubo emisores ni repetidores orientados hacia esta región y tampoco la potencia en los mismos fue calculada para llegar hasta este territorio. Por eso las ondas procedentes del extranjero - que como veremos más adelante se sintonizaron en la regióndebieron contar con el impulso de la climatología y ciertas condiciones astronómicas para alcanzar a la región, una circunstancia que era totalmente dependiente de la fenomenología y no sólo de las posibles instalaciones funcionales que se hubiesen establecido en la región.

\subsection{Las primeras recepciones de televisión}

La puesta en marcha de la televisión pública en España fue un asunto de alcance nacional que quedó perfectamente recogido a través de la prensa $(A B C, 30$ de octubre de 1956: 41). En Asturias se hizo eco tanto la prensa regional (La Nueva España, 30 de octubre de 1956: 16) como la prensa local (Voluntad, 30 de octubre de 1956: 11). Esta primera emisión oficial de TVE se llevó a cabo desde los estudios de provisionales en el Paseo de la Habana en Madrid y se realizó con una escasa potencia radiada que apenas llegaba hasta setenta kilómetros del centro urbano madrileño. (Pérez Sanjuan, 2008).

Tras las primeras emisiones, aún sin llegar TVE a Asturias (Martín-Antón, 2017a), el número de noticias en la prensa regional aumentó significativamente evidenciando un cambio de interés de los informadores hacia el asunto televisivo. Esta presencia informativa despertó la curiosidad de algunos técnicos y aficionados a la electrónica caza señales - que los animó a construir sistemas capaces de captar la señal de la recién inaugurada cadena nacional. Sin embargo, recibir TVE era aún imposible.

Posteriormente se puso en funcionamiento el Centro Emisor de Navacerrada-conocido también como Centro Emisor de La Bola del Mundo o de las Dos Castillas- que fue el centro emisor responsable de aventar la señal hacia el norte, comenzó las emisiones en pruebas en 1959 como recogió el diario Región (13 de octubre de 1959: 9) lo que nos pone en evidencia la muy precaria red de repetidores de televisión que trataba de trasladar la señal entre 1957 y 1959 hasta Asturias. 


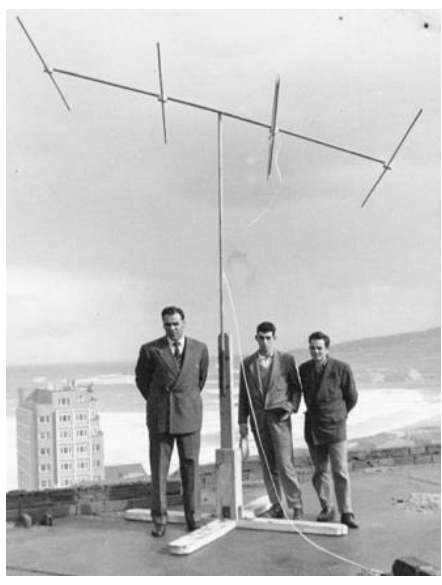

Figura 2. Mercurio y sus empleados, en el año 1957, junto a la antena con la que captaron imágenes del extranjero. Al fondo la playa de Gijón. Fuente: fotografía cedida por Mercurio Martínez García

La mayor parte de la geografía asturiana permaneció con amplios territorios en sombra hasta casi la mitad de la década de 1960 como asegura Martín-Antón (2017b). Este fue uno de los motivos principales por el que esta región fuera uno de los territorios con más salas de televisión y Teleclubs de España. En referencia a este asunto asegura que fue a partir de 1964 cuando se obtuvo una recepción razonable de TVE en la provincia lo que fomentó la presencia de Teleclubs hasta que eso ocurrió. Ello se debió a la complicada orografía, lo que supuso que:

«[...]la implantación de la televisión en Asturias fue muy desigual y no siempre las medidas técnicas que se tomaron aseguraban una buena calidad de recepción. A veces se vio la televisión en un punto y a pocos metros de distancia ya no. En otras ocasiones la imagen se vio de manera intermitente. En todo caso, estas circunstancias no animaban a los asturianos a comprar televisores» (Martín-Antón, 2017: 39)

A pesar de todo, el inicio de las emisiones despertó el interés por captar las emisiones de TVE y animó a los primeros caza señales de la región. Y ello supuso, para su sorpresa, que no sintonizaran TVE; pero si, en cambio, señales extranjeras. En este sentido hemos constatado dos recepciones pioneras fechadas antes de la llegada de la televisión pública estatal a Asturias. Una se logró en Gijón y la otra se obtuvo en Oviedo. El origen de estas ondas, en ambos casos, estaba en el extranjero. Nuestros testigos, tanto Juan Llaneza como Mercurio Martínez, nos han proporcionado la información sobre aquellas sintonizaciones e incluso fueron testigos directos de algunas de las mismas.

En el caso gijonés, el caza señales fue Mercurio Martínez Rodríguez. A principios de 1957, animado por las noticias que llegaban desde Madrid sobre la puesta en marcha de la televisión en España, decidió instalar una antena receptora en la terraza de la azotea del edificio en el que su establecimiento ocupaba uno de los bajos. Quería comprobar si la señal llegaba a Asturias.

Como técnico, Mercurio era conocedor de que la recepción de la televisión en Very High Frequency (en adelante, VHF) no depende exclusivamente del emisor y de la propagación, sino que también estriba en el sistema receptor o antena utilizada. Era sabedor de que una antena más alta y de mayor tamaño recibe más potencia que una antena a menor altura y más pequeña porque la señal encuentra menos obstáculos en su camino y, por tanto, se atenúa menos. 
Se hacen aproximaciones tales como que una antena de cinco metros de altura capta veinticinco veces más que una antena convencional de un metro de altura y esto puede significar recibir entre cien y doscientas veces más que lo que puede captar una persona con una instalación convencional doméstica, sin tener en cuenta otros factores, como la altura a la que se instale (Martín-Antón, 2017a). Por este motivo, Mercurio instaló una antena de grandes dimensiones (ver Figura 2).

El edificio de catorce plantas está ubicado en la calle Uría de Gijón, era de los más altos de la zona y no estaba rodeado por otros de alturas superiores. Aún hoy en día, desde la azotea se puede contemplar el mar Cantábrico y toda la periferia de la villa de Jovellanos sin obstáculo alguno. La señal recogida por la antena que instalaron se bajaba mediante un cable desde el tejado hasta un receptor de televisión ubicado en su establecimiento comercial situado a pie de calle.

Los experimentos de Mercurio para captar señales se iniciaron a finales del año 1957 y gracias al montaje técnico realizado, él y a sus empleados, en el periodo estival de 1958, fueron los primeros en ver una señal de televisión en Gijón. La sorpresa fue que no se sintonizó la cadena española sino una de habla inglesa retransmitiendo una carrera de caballos. Nuestro testigo e informante Mercurio Martínez nos aseguró que la señal fue de la British Broadcasting Corporation (en adelante, BBC).

La información obtenida la verificamos a la vez por otra vía: el diario local Voluntad se hizo eco de esta y otras recepciones posteriores que se produjeron durante los meses siguientes en aquel receptor propiedad de Mercurio. Carbayín, periodista del citado rotativo, aseguró que se captaron también otras señales de televisiones en los idiomas alemán e italiano. Escribió que se recibió la transmisión con la imagen «un poco deformada debido a que el sistema de transmisión es distinto al español, porque los aparatos receptores para uso en España son de diferentes características» (30 de octubre de 1959: 12). Así quedó constancia escrita más de un año después de que en Gijón se recibieron señales de televisiones extranjeras, por primera vez, en agosto de 1958.

En lo que se refiere a Oviedo, el caza señales fue Juan Eladio Llaneza Fernández, un industrial ovetense que contaba con un espíritu curioso, según nuestro testigo e informante Juan Llaneza. A ello se sumaba una amplia formación, recursos y personal cualificado a su disposición debido a que formaban parte de su plantilla de empleados. Entre ellos José María Muñoz Aza, ingeniero de telecomunicaciones y experto en materia de propagación de señal. Aza trabajó años antes para la cadena británica de televisión BBC y era un perfecto conocedor de las instalaciones de las televisiones de Berlín, Ámsterdam y Estambul. Contrastamos esta información en un artículo sin firma del diario Región (28 de noviembre de 1959: 4). 
En la década de los años cincuenta del siglo pasado, Juan Eladio Llaneza era propietario de una vivienda unifamiliar en Santa Marina de Piedramuelle, una parroquia del municipio de Oviedo. En ella se recibieron las primeras señales de televisión que resultaron, también, ser de cadenas extranjeras. El ingeniero construyó en su finca, en 1959, una antena y otras infraestructuras diseñadas por él mismo con la finalidad de recibir la televisión nacional en su receptor Sylvania situado en el interior de la vivienda. Aquella instalación captó también señales de televisiones extranjeras; pero sucedió un año después que se lograsen las primeras en Gijón. Juan Llaneza nos aseguró que se recibieron en el verano de 1959 y se pudo captar una cadena italiana, otra de habla inglesa e incluso de alguna señal procedente de televisiones del otro lado del Telón de Acero. El redactor del diario regional La Nueva España, que firmó como Lac, documentó aquellas sintonizaciones de cadenas de televisión extranjeras cuatro meses después ( 3 de diciembre de 1959: 6).

Tras estas dos recepciones pioneras, no será hasta cuatro años después cuando se constate alguna sintonización más de televisiones extranjeras en Asturias. En 1963, el semanario El Eco de Luarca recogió en un breve incluido en su portada que constataba que en Cadavedo (concejo asturiano de Valdés) se vieron imágenes procedentes de estaciones emisoras de televisión pertenecientes a países de detrás del Telón de Acero (7 de julio de 1963: 1).

Para finalizar sabemos que, entre finales de 1956 y las recepciones documentadas, ambas instalaciones - la de Gijón y la de Oviedo- estuvieron fraguándose y se realizaron pruebas en ellas. Sin embargo, ni nuestros testigos - Juan Llaneza y Mercurio Martínez- ni las fuentes primarias o secundarias, nos han dejado constancia alguna de recepción alguna y por lo tanto debemos obviar cualquier conjetura al respecto. En consecuencia, tras esta primera fase de investigación en la que se evalúan las informaciones de nuestros informantes y su correspondiente contraste con la prensa, se determina a priori que la primera recepción de la que se produjo en Asturias fue en Gijón en agosto de 1958 y un año después, en agosto de 1959, en Oviedo. A continuación, en la fase de verificación y en la de constatación procederos a comprobar si es posible que fueran las ya citadas cadenas extranjeras las sintonizadas en esta provincia en las fechas indicadas por nuestros informantes.

\subsection{Proceso de verificación}

A partir de los resultados que hemos presentado, y de acuerdo con la verificación que planteamos como método de contraste de la información obtenida, fue necesario comprobar qué cadenas de televisión estaban emitiendo de manera regular en 1957 y que estándares de trasmisión de señal utilizaban para radiar. Esta es una información pública y de muy fácil acceso. En un rápido recorrido por los principales países europeos 
evidenciamos que, entre 1957 y 1959, ya estaban emitiendo un número considerable de cadenas que, a continuación, pasamos analizar:

La televisión alemana -de la que luego surgen la Deutsches Fernsehen alemana en 1952 para la Alemania Occidental y la Fernsehen der DDR o DDR-FS para la Alemania Orientallleva inaugurada en Berlín desde el 22 de marzo de 1935.

En Inglaterra funcionaba la Independent Television Authority (en adelante, ITA) que emite desde el 22 septiembre 1955. También lo hace la cadena inglesa BBC desde el 2 de noviembre de 1936 y, a pesar de que sus emisiones se suspendiesen durante la Segunda Guerra Mundial, en las fechas que nos ocupan ya estaba emitiendo con regularidad y normalidad e incluso, según Costa i Badía (1986, p.54), con un sistema de alta definición que prevaleció frente al sistema mecánico alemán. La cadena de televisión de habla inglesa Raidió Teilifís Éireann ${ }^{4}$ (Radio y Televisión de Irlanda o RTÉ irlandesa) carece de nuestro interés ya que sus emisiones fueron posteriores a 1960.

Otras cadenas que estaban en funcionamiento son: la televisión polaca Telewizja Polska (TVP) emitiendo desde Varsovia y operando a partir de 1952; la televisión suiza Télévision Suisse Romande (TSR) desde 1954 emitiendo desde Ginebra; la cadena checa Česká televize (ČST) que lo hace desde 1953 desde Praga; la ORF eins austriaca desde Viena y emitiendo desde 1955. La Perviy Kanal rusa inaugurada en 1951 con sede en Moscú y la Danmarks Radio desde Copenhague, que opera desde 1925. Para finalizar este repaso, la Radiotelevisione italiana (RAI) que inició sus emisiones el día 3 enero de 1954.

En consecuencia, constatamos que existen diferentes cadenas internacionales que ya funcionan a finales de la década de 1950 y que alguna radiaba desde el otro lado del Telón de Acero confirmando este particular al que hacen referencia nuestros testigos.

En referencia a la primera recepción -el momento en el que en Gijón se sintonizó una cadena de habla inglesa- los testigos señalaron a la BBC; pero, su argumento se basó en el idioma ya que nos han declarado que no apreciaron en la pantalla la presencia de ningún logotipo o rótulo identificativo de la cadena. Por lo tanto, hemos indagado para confirmar si efectivamente pudo ser la BBC o la anteriormente mencionada ITA.

Mientras que los ingresos de la BBC procedían fundamentalmente de fondos públicos, los de la ITA se obtienen de cánones de arrendamiento y eso supuso menores presupuestos de implantación. Las antenas de la ITA eran menos potentes y radiaban hacia el centro y el sur de Inglaterra cubriendo: Hampshire, la mayor parte de Dorset, partes de Surrey y Oxfordshire, el sudeste de Inglaterra, Kent o Sussex. Su emisor más potente, en Dover, no entró en funcionamiento hasta 1960. En resumen, la cobertura

${ }^{4}$ Nombre oficial en irlandés. 
principal de la ITA y, por lo tanto, la orientación principal de sus emisores es centro y sureste, por lo que no nos hace pensar que su señal llegase a Asturias.

Por su parte, la BBC contaba con un potente emisor - de los que radiaban con mayor potencia en aquellos años- situado en un punto elevado en Perranporth. La señal emitida desde esta instalación pudo llegar perfectamente a Asturias, al no existir ninguna barrera natural elevada.

En otro orden de cosas, para sintonizar y ver la señal de las citadas cadenas se necesitaba tener un receptor de televisión basado en el sistema de 405 líneas en VHF (Pérez y Zamanillo, 2003). Recordemos que los televisores utilizados tanto por Mercurio como por Eladio eran modelos de las marcas Marconi y Sylvania, es decir, fabricados bajo los parámetros de emisión compatibles con la citada Norma Gerber.

Por lo tanto, en esta segunda etapa del estudio, verificamos que todas las cadenas a las que se refirieron los testigos y la prensa-la cadena inglesa en Gijón y las cadenas: italiana y alemana en Oviedo - ya estaban emitiendo en el verano de 1958 y además lo estaban haciendo con unos parámetros de señal que eran compatibles con los sistemas de recepción -Norma Gerber- de los televisores que, como aseguran nuestros informantes Juan Llaneza y Mercurio Martínez, fueron utilizados en los experimentos.

Por ende, todos los datos aportados por nuestros informantes y respaldados por los artículos encontrados en la prensa se ven, nuevamente, reforzados por el proceso de verificación.

\subsection{Proceso de constatación}

Una vez superada la fase de verificación el último paso fue determinar si las ondas de las televisiones extranjeras que estaban emitiendo entre 1957 y 1959 pudieron llegar a la región - con la tecnología presente en aquel momento- 0 , por el contrario, era imposible que alcanzasen nuestras latitudes. Llegados a este punto, como ya mencionamos en el apartado metodológico, recurrimos a dos informantes cuya razón de ciencia es: la materia astronómica en el caso de Javier Alcolea y, Susana Loredo en asuntos relacionados con la propagación de señales.

Las ondas de televisión necesitan de sistemas repetidores de señal para transportarse de unos lugares a otros ya que se ven muy afectadas por la orografía. Cuando la onda de televisión encuentra un obstáculo -una montaña, por ejemplo- no lo traspasa; pero al chocar con él la señal se dispersa en todas las direcciones del mismo modo que rebota el agua que sale de una manguera al poner la mano en su curso. Este efecto puede lograr que una onda rebotada llegue a sitios en los que no se la espera pudiendo ser sintonizada de una manera casual. 
Otra peculiaridad de la propagación de la señal de televisión es lo fácil que puede verse afectada, en periodos concretos, por fenómenos atmosféricos que potencian su alcance y permiten que sus ondas alcancen grandes distancias. Existen, en consecuencia, dos tipos de influencias: atmosférica y astronómica.

\subsubsection{Influencia atmosférica}

En la década de 1950 las televisiones estaban emitiendo en la banda VHF entre los 41 a los $68 \mathrm{MHz}$, rango de frecuencias conocido como Banda I según la designación que hace la Unión Europea de Radiodifusión (en adelante, UER). La VHF favorece la propagación: a igualdad de potencia la cobertura en la VHF es mayor que en la Ultra High Frequency (en adelante, UHF).

La frecuencia de una onda y su propagación se relacionan de manera inversa, emitir en rangos de frecuencias más bajos conlleva que la señal se radie más lejos. Pero, además, en el rango más bajo de las frecuencias en VHF en ocasiones se producen ciertas singularidades que aumentan el alcance de la señal hasta enormes distancias. A este fenómeno se le conoce como propagación ionosférica. Kitchen y Tremellen (1962) constataron un caso de señales interferentes transoceánicas que se produjeron en receptores en Londres a causa de cadenas de televisión que estaban emitiendo desde los Estados Unidos. Este mecanismo de propagación dominante se produce en la ionosfera y «causa ante todo la reflexión de las ondas radioeléctricas por debajo de aproximadamente $30 \mathrm{MHz}$, puede admitir la propagación en la banda de ondas métricas (30-300 MHz) en ciertas condiciones, durante períodos de tiempo relativamente cortos, y en determinadas regiones del mundo» (ITU-R P.844-1, 1992-1994: 1).

La ionosfera es una región ionizada de la atmósfera superior que tiene unas condiciones extremadamente variables. Dentro de la ionosfera se distinguen varios estratos donde la ionización alcanza valores máximos relativos. Según nuestra informante Loredo Rodríguez, estas capas se designan mediante las letras $D, E$ y $F$ siguiendo un orden creciente de alturas. La última capa, la $F$, se subdivide en dos: F1 y F2. Como consecuencia de las variaciones de la radiación solar, la distribución de la densidad de ionización (medida en electrones $/ \mathrm{m}^{3}$ ) varía en función de diversos factores, tales como la hora, el mes, el año y la situación geográfica.

La capa F2, la que más nos interesa para entender el fenómeno, está situada entre los doscientos cincuenta y los cuatrocientos cincuenta kilómetros de altura desde la superficie. Es la principal capa reflectora para las comunicaciones VHF a larga distancia. De esta capa, Loredo Rodríguez asegura que la densidad de ionización y su altura presentan unas variaciones diarias estacionales según el ciclo de actividad solar. Por ejemplo, al atardecer y de noche -precisamente cuando se solían hacer los experimentos de sintonización de Mercurio y Eladio que hemos explicado- la capa F1 se 
une con la F2 a una altura de unos trescientos kilómetros, lo que aumenta también la propagación de las señales de VHF.

Además del fenómeno de propagación ionosférica ya mencionado, existe una segunda anormalidad que tiene lugar en la troposfera que favorece la propagación de las ondas de televisión hasta distancia o lugares inesperados. La troposfera, capa inferior de la atmósfera, es el lugar en donde ocurren la mayor parte de los fenómenos meteorológicos y es también donde se produce la reflexión troposférica o tropo. Tiene su origen en el cambio del índice de refracción entre dos de sus capas sucesivas con distinta temperatura y grado de humedad facilitando que las señales en VHF alcancen cientos de kilómetros. El tropo se produce especialmente en áreas cercanas a las costas -como es el caso de Asturias-. Bajo determinadas circunstancias meteorológicas cuando una capa de aire caliente queda atrapada entre otras dos más frías- se forma un "conducto troposférico"; una especie de conducto o "guía de ondas" por el cual las señales de VHF pueden circular a lo largo de grandes distancias -hablamos ya de miles de kilómetros-. En resumen, es factible que una señal de televisión alcance distancias tan grandes a consecuencia de fenómenos atmosféricos en condiciones de calor y humedad propias de los periodos estivales.

\subsubsection{Influencia astronómica}

También interfiere considerablemente en la propagación de la señal VHF la influencia astronómica que depende del número de iones libres en la atmósfera. Estos iones aumentan en aquellos períodos en los que existe un mayor número de manchas solares o en verano, momento en el que el sol está más cercano y afecta más a la temperatura de la atmósfera.

El incremento de las radiaciones solares ioniza los gases atmosféricos formando un plasma que refleja las ondas emitidas. En este sentido discurre la investigación de Peña Valverde (2010). Los resultados obtenidos en sus trabajos experimentales son extrapolables, por su semejante comportamiento, a las frecuencias más bajas de la mencionada Banda I.

En otro orden de cosas, tal y como nos aseguró nuestro informante Alcolea Jiménez, sabemos que existe una relación directa entre la ionización y las tormentas solares. La actividad solar no afecta a una zona de la tierra, sino que afecta a nivel planetario, ya que el viento solar impacta sobre todo el planeta. Por eso hoy son muy estudiadas dentro de lo que se ha dado en llamar "tiempo ionosférico" o "tiempo del espacio" debido a que afectan a los satélites y a las comunicaciones. Un número elevado de manchas solares no aumenta necesariamente la propagación, pero un mayor número de manchas solares aumenta la probabilidad de que el número de manchas de gran tamaño sea superior y ello eleva la probabilidad de grandes tormentas solares y, por tanto, aumenta la cantidad de partículas que arrastran los vientos solares contra nuestro 
planeta. En esta circunstancia «puede darse una fuerte transmisión, especialmente durante los años de gran actividad solar, en trayectos largos Norte-Sur que atraviesan el Ecuador geomagnético» (ITU-R P.844-1, 1992-1994: 1). Para comprenderlo mejor, podemos hacer el siguiente símil: que en el cielo aparezcan muchas nubes no indica que vaya a llover; pero a mayor número de nubes es mayor la probabilidad de grandes conglomerados nubosos y que esto suponga lluvia.

Cuando la actividad solar es muy elevada en las latitudes más bajas se producen efectos singulares en las emisiones y comunicaciones. Uno de ellos es precisamente la propagación de ciertas ondas que al rebotar en la ionosfera vuelven a la tierra llegando a lugares situados a grandes distancias desde su punto de origen. «Cerca de los máximos del ciclo de actividad solar, la propagación a larga distancia por la capa F2 es posible durante una fracción importante de tiempo en frecuencias por encima de $30 \mathrm{MHz}$. A bajas latitudes, este efecto se produce hasta $70 \mathrm{MHz}$ ( (Ibid: 1).

Hemos encontrado otros puntos del planeta y momentos en los que se produjeron fenómenos similares y se constataron observaciones de señales de televisión a largas distancias. Por ejemplo, las sucedidas entre 1958 y 1959 que recogió el Chicago Daily Tribune (16 de julio de 1959: 9).

Los rotativos americanos hicieron referencia a importantes alteraciones en la señal de televisión como resultado de la actividad solar en Houston y en Long Island según quedó constancia de ello en infromaciones sin firmar de los diarios The Angeles Times ( 29 de noviembre de 1959: 4) y en el The New York Times (29 de marzo de 1959: 19).

El diario $A B C$, hizo también referencia a esta curiosidad astronómica y sus efectos en el aumento de propagación de la señal de televisión. En la noticia se señalaron a las manchas solares como las responsables del suceso (16 de julio de 1959: 43).

Gracias a que la actividad solar se lleva registrando desde el año 1700, hemos comprobado que, entre los años 1958 y 1959 por día, mes y año, fue muy superior a la media de los cien años anteriores. ${ }^{5}$

Se hace evidente, por lo tanto, que esta actividad solar facilitó la propagación de las señales de televisión constatando que gracias a este fenómeno se produjeran las primeras recepciones llevadas a cabo en Asturias.

\footnotetext{
${ }^{5}$ Datos sobre manchas solares disponibles en: <http://sidc.oma.be>.
} 


\section{Conclusiones}

Una vez realizadas las pesquisas aquí expuestas hemos confirmado que se llevaron a cabo recepciones de televisión en Asturias previas a la llegada de TVE. A lo largo de este proceso de investigación hemos concluido en una cronología más ajustada a los sucesos acaecidos. Las primeras señales se sintonizaron en Gijón en el verano de 1958. También desvelamos el nombre de los dos primeros caza señales asturianos que captaron señales de televisión en la región -Mercurio Martínez Rodríguez y Juan Eladio Llaneza Fernández- otorgándoles, al hacerlo público, el merecido reconocimiento. Además, constatamos con qué medios técnicos contaron y como los utilizaron para lograr la sintonización de aquellas señales. De ambos fue Mercurio Martínez Rodríguez, en Gijón, el primero en sintonizar una señal de televisión en Asturias.

Es necesario destacar también que el testimonio oral ha sido crucial en nuestra investigación ya que nos ha servido para indagar en la dirección adecuada a lo largo de este trabajo y ello se debe a la excepcional calidad de nuestros informantes y su disposición a colaborar en todo momento.

En otro orden de cosas, sabemos que para lograr estas recepciones no fue clave solamente el componente humano, sino también el atmosférico e incluso el astronómico. Ambos se dieron en el periodo estival de 1958 favoreciendo la propagación de las señales de televisión extranjeras y desbancando a TVE como la primera en sintonizarse en la región, como se ha considerado en diferentes trabajos publicados hasta ahora. De hecho, hemos confirmado que fue la BBC la primera cadena de televisión recibida en Asturias.

Por otro lado, y una vez confirmadas estas recepciones consideramos que es preciso, a partir de este ahora, realizar una separación terminológica que distinga claramente entre las primeras recepciones de televisión y las primeras recepciones de TVE. Tras efectuar una revisión detallada de las investigaciones previas que han tratado el asunto de la televisión en Asturias, hemos observado la ausencia de una separación terminológica. Es cierto que estos estudios previos no pretendieron nunca establecer una cronología exhaustiva sobre la llegada de la televisión a la región; pero ello no ha evitado que las fechas que en ellos se recogen no se compilado en publicaciones posteriores ensombreciendo, sin querer, el conocimiento de los sucesos reales y la cierta sucesión de eventos. También se ha observado que a partir de los libros de anécdotas y/o de entretenimiento se ha vinculado la cronología de la televisión exclusivamente a la historia de TVE. Una ausencia de rigurosidad a la que contribuye la GEA, primera obra de referencia en Asturias, tanto por su antigüedad como por su prestigio, al vincular ambos hitos al definir la voz "televisión" vinculándola con el año 1961 simplificando, de este modo, excesivamente la historia de la televisión en Asturias. 
Consideramos por todo ello y a la luz de lo mostrado en este trabajo de investigación que es necesario realizar una reflexión y revisión del fenómeno. Por eso reiteramos necesario delimitar la separación terminológica entre los dos momentos señalados.

Para finalizar, es posible que estas circunstancias y sucesos se repitan de manera similar en otros territorios. Por eso creemos que es importante continuar realizando una revisión histórica del fenómeno de la llegada de la televisión en sus instantes más pretéritos y no solo al nivel asturiano sino incluso a nivel nacional. Eso permitirá conocer la verdad contribuyendo humildemente a mejorar el conocimiento de las generaciones venideras y evitando que otras cronologías erróneas se trasladen a trabajos en las aulas y/o a los futuros estudios de investigación sobre esta materia.

\section{Bibliografía y fuentes}

\section{Referencias Hemerográficas}

Carbayín. (30 de octubre de 1959). "Televisión en Gijón, desde hace un año". Voluntad, p. 12.

CIFRA (30 de agosto de 1952). "Se termina la estructura de la torre más alta de España", ABC, p.18.

EFE (16 de julio de 1959). "Las comunicaciones por radio con Norteamérica, interrumpidas durante cinco horas", $A B C$, p. 43.

Lac. (3 de diciembre de 1959). “¿Cuál es la razón de que en el Cristo se capte, contra toda lógica, la TV?", La Nueva España, p. 6.

SIN FIRMA (28 de noviembre de 1959). "La TV en Asturias". Región, p. 4.

SIN FIRMA (29 de noviembre de 1959) "Spectacular northern lights in Houston", The Angeles Times, p.4

SIN FIRMA (7 de julio de 1963). "La actualidad se llama así...", El Eco de Luarca, p. 1.

SIN FIRMA (30 de octubre de 1956). ABC, p. 41.

SIN FIRMA (30 de octubre de 1956). La Nueva España, p. 16.

SIN FIRMA (30 de octubre de 1956). Voluntad, p. 11.

SIN FIRMA (16 de julio de 1957). Chicago Daily Tribune, p. 9.

SIN FIRMA (29 de marzo de 1959). The New York Times, p. 19. 


\section{Fuentes Orales}

Entrevistas del autor a:

- Alcolea Jiménez, Javier. [Entrevista telefónica], 14 de septiembre de 2011.

- Llaneza Carral, Juan Eladio. Oviedo, 24 de enero de 2012.

- Loredo Rodríguez, Susana. [Informe]. Gijón, 15 de marzo de 2012.

- Martínez García, Mercurio. Gijón, 10 de abril de 2012.

\section{Internet y websites}

Solar Influences Data Analysis Center (SIDC): http://sidc.oma.be

\section{Referencias bibliográficas}

ARIAS RUIZ, A. (1970). La televisión española. Madrid: Publicaciones Españolas.

BAGET HERMS, J. Mạ. (1993). Historia de la televisión en España (1956-1975). Barcelona: Ediciones Feed Back.

BUSTAMANTE, E. (2013). Historia de la radio y la televisión en España. Barcelona: Gedisa

CAÑADA, S. (coord.) et al. (1993). Gran Enciclopedia Asturiana. Vol. XIII. Gijón: Editorial Silverio Cañada.

CAÑEDO RAMOS, A (2018). Televisión del Principado de Asturias: Dinamización y diversidad en el sector audiovisual asturiano (2005-2015). Tesis doctoral. Universidad Carlos III, Madrid, España, disponible en <https://earchivo.uc3m.es/handle/10016/27512>. [Consultado 15 de enero de 2020].

COSTA I BADÍA, P. O. (1986). La crisis de la televisión pública. Barcelona: Paidós Comunicación.

DÍAZ, L. (1994). La televisión en España (1949-1995). Madrid: Alianza Editorial.

FERNÁNDEZ AVELLO, M. (1976). Historia del periodismo asturiano. Oviedo: Ayalga Ediciones. 
GARCÍA BANGO, L. M. (2004). Historia de la televisión en Asturias (1971-1996). Memoria de licenciatura. Oviedo: Departamento de Historia Contemporánea, Facultad de Geografía e Historia, Universidad de Oviedo.

GUIXÉ, J. (2017). "Testimonios, políticas de memoria y patrimonio intangible, usos y ejemplos" en Historia y Comunicación Social no 22.2, p. 381-395. http://dx.doi.org/10.5209/HICS.57850

GÓMEZ ALONSO, R. (2004). "Investigar la historia de la televisión en España: algunos problemas documentales y metodológicos" en Área Abierta [En Línea] no 7. Universidad Complutense de Madrid, disponible en: http://revistas.ucm.es/index.php/ARAB/issue/view/ARAB040413

HERNÁNDEZ RAMOS, P. (2017). “Consideración teórica sobre la prensa como fuente historiográfica" en Historia y Comunicación Social no 22.2, p. 465-477. http://dx.doi.org/10.5209/HICS.57855

ITU-INTERNATIONAL TELECOMMUNICATION UNION, (1992-1994). Factores ionosféricos que afectan a la compartición de frecuencias en las bandas de ondas métricas (30 MHz-3 GHz), recomendación ITU-R P.844-1, (Cuestión UIT-R 218/3), disponible en: https://www.itu.int/dms_pubrec/itu-r/rec/p/R-REC-P.844-1-199408-I!!PDF-S.pdf

KITCHEN, F. A.; TREMELLEN, K.W. (1962). lonospheric influences in Television Reception, Radio Section no 1200. London: Television Convention.

LIMANN, O. (1988). Fundamentos de televisión. Barcelona-México: Boixareu Editores.

MARTÍN-ANTÓN, J. (2017a). La televisión en Asturias. [Tesis doctoral inédita]. Universidad Nacional de Educación a Distancia (UNED), Madrid, España.

- (2017b). “Los Teleclubs. Una revisión acerca de las Salas de Televisión en España y su incidencia en Asturias" en Espacio, Tiempo y Forma. Serie V Historia Contemporánea, no 29, p. 25-62. DOI: http://dx.doi.org/10.5944/etfv.29.2017.15298

MELGAR, L. T. (2003). Historia de la televisión. Madrid: Acento Editorial.

NAVARRO MORENO, J.A. (1999). La televisión Local. Andalucía: la nueva comunicación. Madrid: Editorial Fragua.

ORTEGA MOHEDANO, F. (2008). La televisión en Castilla y León. Salamanca: Ediciones Amarú.

PALACIO, M. (2001). Historia de la Televisión en España. Barcelona: Gedisa.

PÉREZ SANJUAN, O. (2008). Detrás de la cámara. Historia de la Televisión y de sus 50 años en España. Madrid: COIT/AEIT. 
PEÑA VALVERDE, I., (2010). Planning Factors for Digital Local Broadcasting in the $26 \mathrm{MHz}$ Band. Tesis de licenciatura. Bilbao: Universidad del País Vasco.

PEREZ, C.; ZAMANILLO, J.M. (2003). Fundamentos de Televisión Analógica y Digital. Santander: Servicio de Publicaciones de la Universidad de Cantabria.

RODRÍGUEZ MUÑOZ, J. (coord.) et al. (2011). Asturias bajo el franquismo (1937-1975). Oviedo: Editorial Prensa Asturiana.

RUEDA LAFFOND, J.C.; CHICARRO MERINO, M. (2006). La televisión en España. 19562006. Madrid: Editorial Fragua.

RUITIÑA, C. (2013). Historia de la televisión asturiana (1964-2006). Oviedo: Editorial Ámbitu.

RUÍZ DEL OLMO, F. J. (1997). Orígenes de la televisión en España. Málaga: Universidad de Málaga.

SABÉS TURMO, F. (2002) La radio y la televisión local en Aragón. Lleida: Editorial Milenio.

SÁNCHEZ ANTUÑA, R. (2011). La metamorfosis de la caxa tonta, Gijón: VTP editorial.

SANTOS DÍEZ, Mạ. J.; PÉREZ DASILVA, J.A. (2010). La televisión local en el País Vasco. Guipuzkoa: Itxaropena S.A.

SUÁREZ, C. (2004). "Una mirada retrospectiva: así nacieron las ICT'S" en El Instalador, junio, p. 44-46.

TAMARGO, E. (1991). Desventuras radiotelevisivas. Oviedo: ALSA. 